Editorial

\title{
Sugerencias para la organización de la dinámica de vida y comunicación en familias durante la pandemia
}

\section{Suggestions for Organization of Day-to-Day Life and Communication in families in conditions of Pandemic}

\author{
Solovieva, Yulia ${ }^{1,2}$ y Quintanar Rojas, Luis ${ }^{1}$ \\ La dirección consciente del desarrollo psicológico del niño se realiza, antes que nada, a través de \\ la dirección de la relación conductora del niño con la realidad.
}

N. Leontiev

La sociedad humana nunca permanece estática. En cada época histórica, diversos sectores de la sociedad o toda la sociedad en su conjunto, sufre cambios y transformaciones que pueden ser positivos o negativos. Algunas situaciones particulares pueden ser dolorosas o inaguantables para los integrantes de la sociedad.

En el año 2020, a toda la humanidad sin exagerar le ha tocado enfrentarse con una crisis antes desconocida, cuyas razones pueden ser incomprensibles para muchos. Lo que nos toca comprender es que es mejor quedarse en las casas durante un periodo de tiempo que, desgraciadamente, no es previsible conocer hasta ahora. Los miembros de la sociedad deben mostrar una comprensión consciente y voluntaria de toda esta situación con sus consecuencias, de lo cual depende todo nuestro éxito futuro y el bienestar de toda la sociedad, la familia y la personalidad.

Los niños de todas las edades participan, junto con sus padres, en el aislamiento. En este periodo los niños no pueden convivir con sus pares, con sus maestros y amigos de forma directa. Sin embargo, podemos comprender que lo anterior no debe afectar la real comunicación de ellos con todos los integrantes de la sociedad humana. Ningún niño, ni adulto, puede vivir en aislamiento. Nuestro deber y obligación es brindar las condiciones más cercanas a las óptimas para garantizar un adecuado periodo del desarrollo psicológico y la convivencia productiva de los niños y adul- tos en sus familias. Como lo plantea el epígrafe para nuestras sugerencias, la realidad para el niño siempre es mediatizada y dirigida desde afuera, desde la participación colaborativa y activa de los adultos (Leontiev, 1983).

Como psicólogos y neuropsicólogos de la postura que se llama histórico-cultural (Solovieva y Cols., 2019; Solovieva y Quintanar, 2019), podemos hacer algunas recomendaciones y sugerencias en forma de guía para las familias.

Estas sugerencias se aplican a las edades psicológicas desde edad preescolar mayor hasta la edad escolar, es decir, aproximadamente, desde la edad de 5 años.

1. Comunicación. Garantizar que el niño tenga tiempo para la comunicación con sus pares, amigos, compañeros. Esta comunicación puede consistir en platicar, jugar, ver una película, preparar tarea de casa, hablar sobre la tarea de casa, mostar-esultados de tareas de casa que ya se realiaron. Dicha comunicación se puede realizar vía telefónica o por medios audio-visuales. Los adultos pueden y deben sugerir, respaldar y garantizar estas conversaciones que deben ser diaria. Lo ideal es que se hagan por iniciativa de los mismos niños. Obviamente, los niños pueden desear comunicarse también con otros adultos, por ejemplo, con sus maestros o parientes. Esta situación igualmente debe ser garantizada. Es muy importante que el niño hable y se exprese en voz alta con los adultos. El niño puede usar los multimedias, pero también tie-

\footnotetext{
${ }^{1}$ Universidad Autónoma de Tlaxcala

${ }^{2}$ Benemérita Universidad Autónoma de Puebla

*Correspondencia: aveivolosailuy@gmail.com
} 
ne que comunicarse con los demás por medio del lenguaje oral. Es muy importante para su desarrollo y su personalidad.

2. Establecer objetivos en cada tarea. Garantizar que el niño siempre tenga claro lo que tiene que hacer, es decir, que tenga un objetivo. Esto puede ser: dibujar, observar, acomodar, anotar, construir, escribir, resolver. Estas tareas, según la edad y las posibilidades, del niño, se pueden asignar para realizarse junto con alguien más en la casa. Lo importante es que la tarea se lleve a cabo y se complete. Es recomendable decirle al mismo niño que verifique la realización de la tarea de acuerdo al objetivo establecido previamente. No es bueno pasar a otra tarea sin terminar la primera. Una vez terminada, se puede descansar o iniciar la siguiente tarea. Lo esencial es que casi no haya espacios en el día, durante los cuales el niño no tenga un objetivo que se tiene que realizar. Es decir, durante el día es necesario pasar de un objetivo a otro, para que la vida no sea un caos.

3. Tareas conjuntas y divididas entre niños y adultos. En muchas ocasiones, los niños no pueden cumplir con las tareas ellos solos. Muchas tareas se pueden realizar en compañía de adulto. Todo el desarrollo del niño transcurre dentro de su posibilidad para colaborar y ser asistido por los adultos (Tomasello, 2010). La colaboración activa se puede comprender como una productiva $\mathrm{y}$ activa imitación en lugar de una pasiva y reproductiva copia mecánica de la conducta (Vigotsky, 2012; Obujova y Shepovalenko, 2013). Si en casa hay varios adultos, ellos pueden ponerse de acuerdo para sustituir unos a otros en las tareas que van a realizar con los niños. Con tareas no nos referimos a las tareas escolares encargadas por los maestros, sino a diversas tareas domésticas o lúdicas. Por ejemplo, ver películas, construir rompecabezas, jugar "Domino" u otros juegos de mesa, acomodar libros y ropa, cambiar la decoración y la distribución de los objetos de la casa, regar el jardín, cocinar, limpiar. Los adultos deben incluir a los niños en todo esto, no los deben dejar solos. Los niños aún no pueden establecer sus propios objetivos sin la guía y la participación del adulto. El adulto introduce los objetivos y los medios en todas las tareas que el niño debe lograr, participando como su guía y colaborador activo e in- teresado. Así es cómo L.S. Vigotsky, el fundador del enfoque histórico-cultural en psicología ha determinado el rol del adulto en la vida del niño. El adulto establece la "zona del desarrollo próximo" del niño (Vigotsky, 2012), no puede estancarse o contentarse con los logros del pasado, sino que siempre se orienta en las necesidades del futuro. Lo mejor es que todo eso lo hagan juntos los adultos y los niños, pero no necesariamente todos lo que están en la casa. Los adultos pueden distribuir y compartir sus actividades, así como la participación de los niños en ellas a lo largo de la jornada. Por ejemplo, con un adulto el niño puede trabajar en jardín, mientras que con el otro participar en la preparación de alimentos. Esto lo hace menos cansado, más interactivo y comunicativo y no necesariamente involucra a todos los habitantes de la casa a lo largo de la jornada en la realización de las mismas tareas. Es muy útil utilizar en el lenguaje cotidianas las expresiones imperativas en plural en lugar del singular. Por ejemplo, en lugar decir: "tienes que regar plantas" o "tienes que hacer tu tarea", es mejor decir: "vamos a regar las plantas juntos", "pueden iniciar hacer tu tarea, y luego juntos la revisaremos", "vamos a ver qué nos hace falta a cambiar en esta sala" o "¿cómo podremos organizar mejor tus juguetes para tenerlos siempre a mano?"

4. Lectura diaria. Para los niños, la lectura debe ser su actividad diaria. Los adultos pueden elegir los libros de cuentos que les gusten a ellos mismos. Los adultos les pueden leer a los niños en voz alta, si los niños aún no pueden leer solos. Sin embargo, a lo largo de toda la escuela primaria es válido leer en voz alta a los niños. Libros tienen que ser interesantes y no necesariamente deben ser parte de tareas escolares. La lectura debe ser placentera y se debe convertir en una actividad intelectual cotidiana diario que produce el gusto y el agrado (Solovieva y Quintanar, 2020; Quintanar y Solovieva, 2020).

\section{Cambio y flexibilidad en la actitud} $\mathrm{y}$ tareas. Los adultos siempre deben contar con varias opciones de tareas para proponer y realizar para un mismo momento. No se debe tratar de una única opción obligatoria que debe ser realizada. Los adultos pueden darles chance a los niños a elegir entre varias opciones que son viables y pueden realmente ser 
realizadas por los niños junto con sus padres en los hogares. No se puede proponer algo que no se puede realizarse ni alcanzarse de una forma concreta. Las tareas que se proponen deben ser interesantes, curiosas, agradables y alegres. ¡No es necesario frustrarse y frustrar más a los niños!

6. ¡Mejor descanso es el cambio de la actividad! Esta frase puede servir de guía para la organización de la jornada. En ningún momento debe predominar la sensación de que nada se está haciendo. Tanto niños, como adultos deben tener sensación de que están realizando algo interesante, algo útil, algo necesario y que, para esto, se están apoyando entre ellos.

7. Salir a la calle. Es necesario que los niños tengan la oportunidad de salir a la calle diariamente, junto con los adultos con todas las medidas sanitarias establecidas. Salir al parque o a las calles cercanas a caminar no representa ningún peligro, siempre y cuando no se unen muchas personas. Los adultos les pueden mostrar a los niños objetos de naturaleza y sociedad que son interesantes, curiosas, novedosas, que se relacionan con la temporada y con las costumbres. Los adultos pueden turnar para salir con los niños. Lo recomendable es salir de paseo diario por lo menos una hora al día. La salida a la calle siempre debe ser planeada, explicada y comunicada al niño con anticipación. Esta salida debe convertirse en una parte del día que se valora y se espera con alegría. Durante el paseo el adulto no puede permanecer callado o abrumado con sus propios problemas, sino debe explicar todo al niño, todos los objetivos del paseo y todas las cosas y situaciones que se observan. El paseo no puede ser confundido con la expresión de "ir de compras". Se trata de algo especial que no puede ser reducido a la necesidad de hacer compras. Al mismo tiempo, el paseo no significa tampoco que nada puede ser comprado en el camino.

Esta costumbre puede ayudar a romper la rutina, distraerse y activarse físicamente. Las salidas pueden variarse según las condiciones climáticas y los lugares que pueden ser visitados sin alteración de las normas sanitarias establecidas en cada localidad. No salir a calle es equivalente privar a los niños de una importante posibilidad de comunica- ción con la naturaleza y la sociedad.

Tengamos esperanza de las familias puedan utilizar con provecho estos tiempos en nuestras casas y los lugares públicos accesibles. Además, es el momento de comprender y valorar mucha más nuestra cultura, nuestra comunicación, nuestra bondad y nuestro derecho de libre reflexión y expresión. Las puertas de las casas pueden estar cerradas, pero no así nuestras almas. Tenemos que aprender a ser mejores todos para poder corregir las grandes imperfecciones que hemos tenido como sociedad y como individuos, porque las pequeñas imperfecciones son la parte propia de nuestra vida y actividad.

Nuestras consignas primarias deben ser la tolerancia, respecto y confianza mutua entre niños y adultos.

\section{Referencias}

Leontiev, A.N. (1983). Obras psicológicas escogidas. Moscú: Universidad estatal de Moscú.

Obujova, L.F. \& Shepovalenko, I.V. (2013). La imitación en niños preescolares. En Solovieva, Y. y Quintanar, L. (comp) Antología del desarrollo psicológico del niño en edad preescolar (pp.59-66). México: Trillas.

Quintanar, L. \& Solovieva, Yu. (2020). Importancia de la teoría de la actividad. En: V. Covarrubias Salvatori. Bases para la introducción y el desarrollo del pensamiento científico en la niñez y la preadolescencia. 111-172. Puebla: CONCYTEP.

Solovieva, Y. \& Quintanar-Rojas, L. (2019). La metodología formativa en la psicología histórico cultural (pp.157-179). Madrid: Editorial EOS.

Solovieva Yu., Akhutina T, Quintanar L, Hazin I. (2019). Historical-Cultural Neuropsychology: a systemic and integral approach of psychological functions and ther cerebral bases. Estudos de Psicología 24 (1): 65-75. DOI: 10.22491/1678-4669.20190008

Solovieva, Yu. y Quintanar, L. (2020). Enseñanza y desarrollo de la comprensión y la producción del lenguaje. México: CONCYTEP.

Tomasello, M. (2010). ¿Por qué coopermos? España: Katz.

Vigotsky, L. S. (2012). Obras Escogidas - IV. Problemas del adolescente. Problemas de la psicología infantil. Madrid: Machado Nuevo Aprendizaje. 